\title{
ORIGINAL ARTICLE Diagnosis and body mass index effects on hippocampal volumes and neurochemistry in bipolar disorder
}

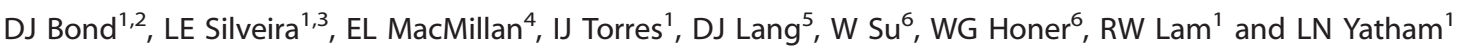

We previously reported that higher body mass index (BMI) was associated with greater hippocampal glutamate+glutamine in people with bipolar disorder (BD), but not in non-BD healthy comparator subjects (HSs). In the current report, we extend these findings by examining the impact of BD diagnosis and BMI on hippocampal volumes and the concentrations of several additional neurochemicals in 57 early-stage BD patients and 31 HSs. Using 3-T magnetic resonance imaging and magnetic resonance spectroscopy, we measured bilateral hippocampal volumes and the hippocampal concentrations of four neurochemicals relevant to BD: $N$-acetylaspartate $+N$-acteylaspartylglutamate (tNAA), creatine+phosphocreatine (Cre), myoinositol (Ins) and glycerophosphocholine+phosphatidylcholine (Cho). We used multivariate factorial analysis of covariance to investigate the impact of diagnosis (patient vs HS) and BMI category (normal weight vs overweight/obese) on these variables. We found a main effect of diagnosis on hippocampal volumes, with patients having smaller hippocampi than HSs. There was no association between BMI and hippocampal volumes. We found diagnosis and BMI effects on hippocampal neurochemistry, with patients having lower Cre, Ins and Cho, and overweight/obese subjects having higher levels of these chemicals. In patient-only models that controlled for clinical and treatment variables, we detected an additional association between higher BMI and lower tNAA that was absent in HSs. To our knowledge, this was the first study to investigate the relative contributions of BD diagnosis and BMI to hippocampal volumes, and only the second to investigate their contributions to hippocampal chemistry. It provides further evidence that diagnosis and elevated BMI both impact limbic brain areas relevant to BD.

Translational Psychiatry (2017) 7, e1071; doi:10.1038/tp.2017.42; published online 28 March 2017

\section{INTRODUCTION}

Over two-thirds of Americans are overweight (33\%) or obese $(39 \%) .{ }^{1}$ Obesity is one of the strongest risk factors for developing diabetes, hypertension, heart disease, stroke and cancer, and it is the second-leading cause of excess morbidity and mortality in the United States after smoking. ${ }^{2-4}$ Patients with bipolar disorder (BD) are even more likely to be obese than the overall population-in fact, obesity rates are over $60 \%$ greater in BD patients. ${ }^{5}$ Not surprisingly, they also suffer more metabolic illnesses, including $25 \%$ higher rates of hypertension and $200-300 \%$ higher rates of diabetes. $^{6-12}$ Much of this excess medical burden is directly attributable to obesity, as shown by a population-based study that reported that obese BD patients had $35-96 \%$ greater rates of hypertension, arteriosclerosis and myocardial infarction than normal-weight patients. ${ }^{5}$

Animal models demonstrate that the health consequences of obesity are caused by body mass index (BMI)-related changes in adipose tissue physiology and in the blood levels of biomarkers made by adipose tissue, such as inflammatory cytokines, adipokines, and pro-oxidative and thrombotic factors. ${ }^{13-16}$ This culminates in multiorgan endothelial dysfunction, the final common pathway for obesity-related medical complications. ${ }^{17}$ Obesity is associated with similar biomarker alterations in humans, and many of these biomarkers cross the blood-brain barrier. ${ }^{18-23}$
Thus, it stands to reason that the human brain will be susceptible to obesity-related pathology. Supporting this hypothesis, BMIrelated endothelial damage has been demonstrated in the brain, and age-related brain volume reductions are more pronounced in primates and humans with higher BMls. ${ }^{17,24-26}$ Diet-induced obesity in a mouse model of Alzheimer's disease resulted in increased $\beta$-amyloid production, whereas humans who are obese in midlife have a twofold increased risk of developing dementia. ${ }^{27,28}$ Obesity is also a risk factor for other brain diseases including multiple sclerosis and Parkinson's disease. ${ }^{29-32}$

These facts, coupled with the high rate of obesity in BD and evidence that obese patients have a more severe psychiatric illness course than normal-weight patients, ${ }^{5,33-36}$ led us and others to investigate the impact of elevated BMI on brain illness severity in $\mathrm{BD}$. Using magnetic resonance imaging (MRI), we found BMIrelated gray and white matter (GM and WM) volume reductions and decreased WM integrity in limbic brain areas in patients, but not non-BD comparison subjects. ${ }^{37-39}$ The volume reductions were particularly pronounced in the temporal lobes, especially the right temporal lobe. Our group also demonstrated BMI-related increases in hippocampal glutamate+glutamine in patients. ${ }^{40}$ Elevated glutamate+glutamine is the most consistently reported neurochemical abnormality in BD. ${ }^{41}$ These findings thus suggest that brain areas vulnerable in $\mathrm{BD}$ experience further BMI-related

\footnotetext{
${ }^{1}$ Mood Disorders Centre, Department of Psychiatry, University of British Columbia, Vancouver, BC, Canada; ${ }^{2}$ Department of Psychiatry, University of Minnesota Medical School, Minneapolis, MN, USA; ${ }^{3}$ Laboratory of Molecular Psychiatry, Centro de Pesquisas Experimentais, Hospital de Clínicas de Porto Alegre and INCT for Translational Medicine, Porto Alegre, Brazil; ${ }^{4}$ Department of Medicine (Neurology), University of British Columbia, Vancouver, BC, Canada; ${ }^{5}$ Department of Radiology, University of British Columbia, Vancouver,

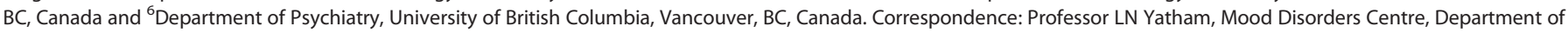
Psychiatry, University of British Columbia, Room 2C7-2255 Wesbrook Mall, Vancouver, BC, Canada V6T 2 A1.
}

E-mail: yatham@mail.ubc.ca

Received 14 August 2016; revised 14 November 2016; accepted 15 January 2017 
damage, so that higher BMI exacerbates the neuropathology of $\mathrm{BD}$.

In the current report, we extend these investigations by examining the impact of elevated BMI on hippocampal volumes and the concentrations of several additional neurochemicals in early-stage BD patients. To evaluate the specificity of our findings to $\mathrm{BD}$, we also included a comparison group of non-BD healthy subjects (HSs). The hippocampus plays important roles in reward processing and emotional memory. A recent meta-analysis reported hippocampal volume reductions in BD, especially in younger patients. ${ }^{42-44}$ The hippocampus also appears to be particularly sensitive to obesity-induced damage, even relative to other brain areas. ${ }^{45}$ The neurochemicals we measured are all relevant to $\mathrm{BD}$ and include $\mathrm{N}$-acetylaspartate, a marker of neuron and myelin function; creatine, which plays a key role in cellular energetics; myoinositol, a second messenger important in phosphoinositol intracellular signalling cascades; and phosphatidylcholine/glycerophosphocholine, which are important in neuronal and glial cell membrane biosynthesis. We hypothesized that BD diagnosis and higher BMI would both be associated with smaller hippocampal volumes and neurochemical abnormalities, and that the impact of BMI would be greater in patients than HS.

\section{MATERIALS AND METHODS}

\section{Systematic Treatment Optimization Program for Early Mania}

The Systematic Treatment Optimization Program for Early Mania is a study of clinical outcomes, brain morphology and neurochemistry following the first manic episode in patients with $\mathrm{BD}^{46}{ }^{46}$ It is based at the University of British Columbia Mood Disorders Centre in Vancouver, Canada. In brief, BD patients aged 14-35 years who experienced their first DSM-IV-TR-defined manic/mixed episode in the preceding 3 months were recruited from the Mood Disorders Clinical Research Inpatient Unit, the Mood Disorders Outpatient Program and affiliated community sites. To capture the full spectrum of BD patients seen in clinical practice, patients with comorbid psychiatric and substance use disorders could be enrolled so long as the primary diagnosis was BD. HSs aged 14-35 years with no history of psychiatric illness were recruited from the greater Vancouver metropolitan area through advertisements and online forums such as Craigslist. Patients and HSs with histories of head trauma with the loss of consciousness were excluded. The University of British Columbia Clinical Research Ethics Board approved the Systematic Treatment Optimization Program for Early Mania and written informed consent was obtained prior to any study procedures taking place.

\section{Clinical assessment}

At enrolment, the diagnoses of BD and first manic/mixed episode were made based on a comprehensive interview with an academic research psychiatrist, and confirmed with the Mini-International Neuropsychiatric Interview. ${ }^{47}$ HSs were also administered the Mini-International Neuropsychiatric Interview, and were enrolled if they had no personal or family history (in first-degree relatives) of psychiatric illness. Sociodemographic and clinical data were collected using a standardized protocol. Mood and psychotic symptoms were quantified in patients with the Young Mania Rating Scale, the Montgomery-Asberg Depression Rating Scale, and the Positive and Negative Syndrome Scale. Patients received treatment for BD according to clinical practice guidelines from the Canadian Network for Mood and Anxiety Treatments. ${ }^{48,49}$ Subjects were weighed in a non-fasting state in light clothing with footwear removed. BMI was calculated as weight $(\mathrm{kg}) /$ height (m). ${ }^{2}$ Underweight was defined as $\mathrm{BMI}<18.50$, normal weight as $\mathrm{BMI}=$ $18.50-24.99$, overweight as $\mathrm{BMI}=25.00-29.99$ and obesity as $\mathrm{BMI} \geqslant 30.00 .{ }^{50}$

\section{MRI/MRS protocols and data extraction}

T1-weighted MR images were acquired with a Philips Achieva 3-Tesla scanner (Best, The Netherlands), typically on the same day as clinical assessment. A three-dimensional axial inversion recovery-weighted spoiled gradient recalled sequence with the following parameters was used: field of view $=25.6 \mathrm{~cm}$, matrix $=256 \times 200$, isotropic voxels $\left(1 \times 1 \times 1 \mathrm{~mm}^{3}\right)$, autoshim, repetition time/echo time $=7.6 / 3.5 \mathrm{~ms}$, transmit/ receive head coil, flip angle $=8^{\circ}$, SENSE $=0$ and $1 \mathrm{~mm}$-thick contiguous
180 slices of the whole brain. Hippocampal volumes were extracted using Freesurfer v5.3 (http://surfer.nmr.mgh.harvard.edu) subcortical segmentation. The GM, WM and cerebrospinal fluid (CSF) composition of the magnetic resonance spectroscopy (MRS) voxel was determined with the FSL v4.1.9 FAST tool (FMRIB Software Library; www.fmrib.ox.ac.uk/fsI/). ${ }^{51,52}$

Proton-MRS ( ${ }^{1} \mathrm{H}-\mathrm{MRS}$ ) signals were acquired with the Philips 3-T unit. T2weighted coronal, sagittal and axial images were used to prescribe two $30 \times 15 \times 15 \mathrm{~mm}$ voxels in the left and right hippocampi. Each voxel was placed with its long axis angled along the hippocampus. Its position in the medial/lateral and superior/inferior directions was adjusted to include the maximum amount of hippocampus and avoid CSF. Screen captures of the slice positioning and anatomical landmarks for voxel placement were acquired for each subject. These were referenced by the scanning technologist to ensure consistency of voxel placement across subjects. Voxel placement and tissue composition are shown in Supplementary Figure S1a. Point-resolved spectroscopy with echo time $=35 \mathrm{~ms}$, repetition time $=2000 \mathrm{~ms}$ and water suppression via chemical shift selective suppression excitation were used to acquire the spectra. One hundred twenty-eight water-suppressed and 16 non-water-suppressed averages were acquired from each voxel. The non-water-suppressed signals were used for eddy current correction and to reference metabolite signals.

Hippocampal concentrations of four metabolites- $\mathrm{N}$-acetylasparate $+\mathrm{N}$ acetylaspartylglutamate (tNAA), creatine+phosphocreatine (Cre), myoinositol (Ins), and glycerophosphocholine+phosphatidylcholine (Cho)-were extracted using LCModel v. $6.3^{53}$ and normalized to the unsuppressed water spectrum. Sample MRS spectra from a patient and a HS are displayed in Supplementary Figure S1b. Metabolite-to-water ratios were converted to institutional absolute concentrations in millimolar units by correcting for the mean water concentration of the voxel (taking into account the fractions of GM, WM and CSF in the voxel and their respective water concentrations), while accounting for water and metabolite signal T1 and T2 relaxations (Supplementary Materials and Methods). Values for water and metabolite $\mathrm{T} 1$ and $\mathrm{T} 2$ relaxation times were taken from the literature. ${ }^{54,55}$ The tissue composition of the MRS voxel and measures of MRS data quality, including signal-to-noise ratio and full width at half maximum, is shown in Supplementary Table S1.

\section{Data analyses and statistics}

Statistical analyses were carried out using IBM SPSS Statistics for Windows 22.0 (SPSS, Chicago, IL, USA). Comparisons were two-tailed, with a significance level of $a=0.05$. We examined sociodemographic and clinical variables with $t$-tests, $X^{2}$-tests and Fisher's exact test as appropriate. Our primary and secondary analyses are specified below. We did not otherwise correct for multiple comparisons. Statistical assumptions appropriate to the tests, including normality of dependent variables and homogeneity of variances, were met.

Primary analyses. Our main objective was to investigate the association of diagnosis, BMI category, and their interaction with hippocampal volumes and neurochemistry. To determine whether diagnosis (BD patient vs HS) and BMI category (normal weight vs overweight/obese) were associated with hippocampal volumes, we created a factorial multivariate analysis of covariance (MANCOVA) model. Diagnosis and BMI category were factors, and left and right hippocampal volumes were the dependent variables. To determine whether the impact of BMI differed in patients and HSs, a diagnosis $\times \mathrm{BMI}$ category interaction term was also included. Age and years of education were covariates. A positive result for diagnosis, BMI category, or the interaction was followed up with analyses of covariance including these three factors to assess left and right hippocampal volumes separately. Because some published reports on hippocampal volumes in $\mathrm{BD}$ adjusted for total intracranial volume (TICV; total GM+total WM+CSF), whereas others did not (for an in-depth review see Otten and Meeter ${ }^{44}$ ), we carried out these analyses with and without adjusting for TICV.

To determine whether diagnosis, BMl category and their interaction were associated with overall hippocampal neurochemistry while minimizing multiple comparisons, we created a factorial MANCOVA model. Left and right tNAA, Cre, Ins and Cho were dependent variables, and diagnosis, BMI category and their interaction were factors. Covariates included age and years of education. To ensure that neurochemical findings were independent of diagnosis- or BMI-related differences in hippocampal volumes or the GM/WM/CSF composition of the MRS voxels, these were also covariates. A positive result for diagnosis, BMI or the interaction was followed up with analyses of covariance including these factors to assess each metabolite separately. We excluded poor-quality data for individual 
metabolite values by (1) multiplying the \%s.d. error from LCModel by the corresponding absolute concentration ( $\mathrm{mm}$ ) to obtain the absolute error estimate, and (2) rejecting data when the absolute error estimate was $>30 \%$ of the median metabolite concentration across all subjects. Compared with the conventional threshold of rejecting data with \%s.d. error estimates $>20 \%$, this method ensures that there is less bias towards rejecting low-concentration metabolite values. ${ }^{56}$

Secondary outcomes. We also constructed multivariate multiple regression models separately in patients and HSs to investigate the impact of the continuous variable of $\mathrm{BMI}$ on hippocampal volumes and neurochemistry in the two groups independently. In patients, this allowed us to assess the impact of BMI on these measures while adjusting for confounding clinical and medication variables. In $\mathrm{HSs}$, it was an important confirmatory analysis as only $N=6 \mathrm{HS}$ s were overweight/obese, giving us relatively low statistical power to detect BMI category effects in HSs. The regressions, in contrast, allowed us to look for a BMl effect over the entire continuous range of values. In the volumetric regressions, left and right hippocampal volumes were the dependent variables. Predictors for patients included BMI; Young Mania Rating Scale, Montgomery-Asberg Depression Rating Scale, and Positive and Negative Syndrome Scale scores; treatment with mood stabilizers and second-generation antipsychotics; age; and years of education. For $\mathrm{HSs}$, they included BMI, age and years of education. As with the factorial models, these were carried out with and without controlling for TICV. In the neurochemical multivariate regressions, left and right tNAA, Cre, Ins and Cho were the dependent variables. Predictors for patients included Young Mania Rating Scale and Montgomery-Asberg Depression Rating Scale scores, treatment with mood stabilizers and second-generation antipsychotics, BMl, age, years of education, hippocampal volumes, and the composition of the MRS voxels. Predictors for HSs included BMI, age, years of education, hippocampal volumes and the composition of the MRS voxels.

\section{RESULTS}

Participants

Fifty-seven of 71 consecutively enrolled patients and 31 of 42 HSs enrolled in the Systematic Treatment Optimization Program for Early Mania had baseline BMI and MR data, and were included in the volumetric analyses. Participants with missing data had declined to be weighed or to undergo the MR procedure. Three patients and $1 \mathrm{HS}$ were excluded from the neurochemical analyses for having artefacts in their MRS data or having an absolute error estimate $>30 \%$ of the median metabolite concentration for one or more metabolites, leaving 54 patients and $30 \mathrm{HS}$ for these.

Patients and HSs were well matched on sociodemographic characteristics, except that HSs had more years of education (Table 1). In keeping with their early illness stage, patients and HSs had similar mean BMls and proportions with normal weight, overweight and obesity. Ninety-three percent of patients were treated with mood stabilizers and/or second-generation antipsychotics (Table 2). Seventy-five percent met a stringent definition of euthymia (Montgomery-Asberg Depression Rating Scale $<12$ and Young Mania Rating Scale $<12$ ), 14\% had subsyndromal depressive or hypomanic symptoms and $11 \%$ were depressed or manic.

Diagnosis, BMI and hippocampal volumes

Factorial MANCOVA. The factorial MANCOVA model without adjustment for TICV detected a significant main effect of diagnosis on hippocampal volumes $(F[2,81]=6.771, P=0.002)$. There was no main effect of $B M I$ category $(F[2,81]=1.741, P=0.18)$ and no diagnosis $\times \mathrm{BMI}$ interaction $(\mathrm{F}[2,81]=1.729, P=0.18)$. Follow-up factorial analyses of covariance showed that right hippocampal volume was significantly smaller in patients than HSs (left: $2.4 \%$ smaller, 4.07 [0.39] vs 4.17 [0.44] $\mathrm{ml}, \mathrm{F}[1]=1.190, \mathrm{df}=1, P=0.28$; right: $5.2 \%$ smaller; 4.19 [0.41] vs $4.42[0.51] \mathrm{ml} ; \mathrm{F}[1]=6.757$, $P=0.01$ ) (Figure 1). The results were unchanged when TICV was included as a covariate.
Table 1. Sociodemographic characteristics of BD patients and healthy subjects

\begin{tabular}{|c|c|c|c|}
\hline & $\begin{array}{l}\text { BD patients } \\
(\mathrm{N}=57)\end{array}$ & $\begin{array}{l}\text { Healthy subjects } \\
\qquad(\mathrm{N}=31)\end{array}$ & P-value \\
\hline & Mean (s.d.) & Mean (s.d.) & \\
\hline BMI & $24.1(3.9)$ & $23.1(2.8)$ & 0.24 \\
\hline Age & $22.7(4.5)$ & $22.9(4.5)$ & 0.84 \\
\hline \multirow[t]{2}{*}{ Years of education } & $13.9(2.3)$ & $15.1(2.6)$ & 0.03 \\
\hline & Percent (N) & Percent (N) & \\
\hline BMI category & & & 0.28 \\
\hline Normal weight & $64.9 \%(37)$ & $80.6 \%(25)$ & \\
\hline Overweight & $26.3 \%(15)$ & $16.1 \%(5)$ & \\
\hline Obese & $8.8 \%(5)$ & $3.2 \%(1)$ & \\
\hline Gender & & & 0.84 \\
\hline Male & $47.4 \%(27)$ & $45.2 \%(14)$ & \\
\hline Female & $52.6 \%(30)$ & $54.8 \%(17)$ & \\
\hline $\begin{array}{l}\text { Ethnicity (self- } \\
\text { reported) }\end{array}$ & & & 0.11 \\
\hline Caucasian & $78.9 \%(45)$ & $64.5 \%(20)$ & \\
\hline Asian & $17.5 \%(10)$ & $35.5 \%(11)$ & \\
\hline Other & $3.5 \%(2)$ & $0 \%(0)$ & \\
\hline
\end{tabular}

Table 2. Clinical and treatment characteristics of BD patients

\begin{tabular}{|c|c|}
\hline & Mean (s.d.) \\
\hline \multicolumn{2}{|l|}{ Rating scale scores } \\
\hline YMRS & $3.7(5.9)$ \\
\hline MADRS & $6.0(8.0)$ \\
\hline PANSS-positive scale & $7.7(1.5)$ \\
\hline \multirow{3}{*}{$\begin{array}{l}\text { Duration of first manic/mixed episode (days) } \\
\text { Total duration of mood disorder (years; including } \\
\text { previous depressions and hypomanias) }\end{array}$} & $60.2(49.8)$ \\
\hline & $2.9(4.2)$ \\
\hline & Percent (N) \\
\hline \multicolumn{2}{|l|}{ Mood state ${ }^{\mathrm{a}}$} \\
\hline Euthymic (MADRS < 12 and YMRS < 12) & $75.0 \%(42)$ \\
\hline Subsyndromal depression (MADRS 12-19) & $7.1 \%(4)$ \\
\hline Depressed (MADRS $\geqslant 20)$ & $8.9 \%(5)$ \\
\hline Hypomanic (YMRS 12-19) & $7.1 \%(4)$ \\
\hline Manic (YMRS $\geqslant 20)$ & $1.8 \%(1)$ \\
\hline \multicolumn{2}{|l|}{ Pharmacotherapy } \\
\hline Mood stabilizer & $86.0 \%(49)$ \\
\hline Second-generation antipsychotic & $78.9 \%(45)$ \\
\hline Mood stabilizer+antipsychotic & $71.9 \%(41)$ \\
\hline No medication & $7.0 \%(4)$ \\
\hline Previous depressive episode ${ }^{a}$ & $53.6 \%(30)$ \\
\hline Previous hypomanic episode ${ }^{a}$ & $19.6 \%(11)$ \\
\hline \multicolumn{2}{|l|}{ Lifetime comorbidity } \\
\hline Anxiety disorder ${ }^{\mathrm{a}}$ & $10.7 \%(6)$ \\
\hline Alcohol dependence $^{\mathrm{b}}$ & $3.6 \%(2)$ \\
\hline Drug dependence ${ }^{\mathrm{b}}$ & $8.9 \%(5)$ \\
\hline
\end{tabular}

Abbreviations: BD, bipolar disorder; MADRS, Montgomery-Asberg Depression Rating Scale; PANSS, Positive and Negative Syndrome Scale; YMRS, Young Mania Rating Scale. ${ }^{\mathrm{a}} N=56$; one value missing. ${ }^{\mathrm{b}} N=55$; two values missing. 


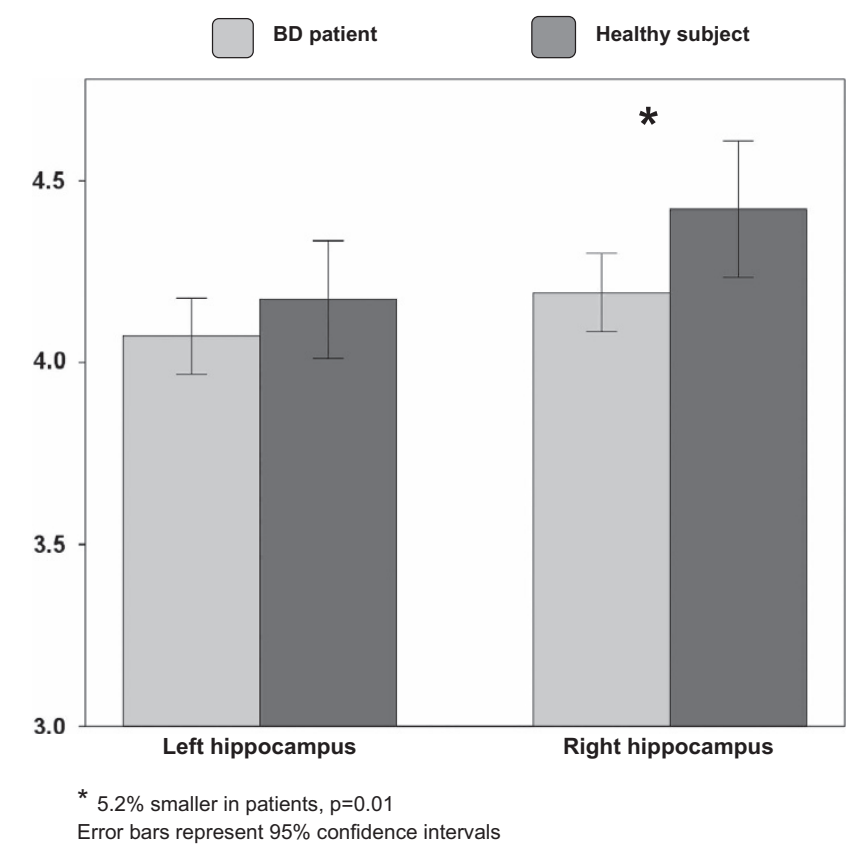

Figure 1. Left and right hippocampal volumes in bipolar disorder (BD) patients and healthy subjects.

Linear regression models. In keeping with the results of the MANCOVA, the linear regressions showed that BMI did not predict hippocampal volumes in patients or HSs (all $P>0.34$ ). Except for TICV, sociodemographic variables in patients and HSs did not predict hippocampal volumes. Clinical and treatment variables in patients also did not predict hippocampal volumes.

\section{Diagnosis, BMI and hippocampal neurochemistry}

Factorial MANCOVA. Factorial MANCOVA detected a significant main effect of BMI category on overall hippocampal neurochemistry $(F[8,65]=2.108, P<0.05)$. There was no main effect of diagnosis $(F[8,65]=1.155, P=0.34)$ and no diagnosis $\times B M l$ interaction $(F[8,65]=0.827, P=0.58)$. In the follow-up analyses of covariance, both BMI category and diagnosis effects were seen for right Cre, right Ins and right Cho. Each of these metabolites had higher concentrations in overweight/obese than normal-weight subjects (Cre: $3.0 \%$ higher, 8.69 [1.04] vs 8.44 [1.24] $\mathrm{mm}, \mathrm{F}$ $[1]=6.203, P=0.02 ;$ Ins: $14.2 \%$ higher, $7.73[2.36]$ vs $6.77[1.93] \mathrm{mm}$, $\mathrm{F}[1]=7.201, P=0.009$; Cho: $3.2 \%$ higher, $2.60[0.36]$ vs $2.52[0.44]$ $\mathrm{mm}, \mathrm{F}[1]=3.907, P=0.05)$, and lower concentrations in patients than HSs (Cre: $3.7 \%$ lower, 8.40 [1.20] vs 8.72 [1.14] $\mathrm{mm}, \mathrm{F}$ $[1]=6.191, P=0.02 ;$ Ins: $2.1 \%$ lower, 7.01 [2.02] vs 7.16 [2.27] mM, F $[1]=4.594, P=0.04$; Cho: $3.8 \%$ lower, 2.51 [0.46] vs $2.61[0.44] \mathrm{mM}$, $\mathrm{F}[1]=4.138, P=0.05)$.

Linear regression models. Although diagnosis $\times \mathrm{BMI}$ category interactions were not detected in the above models, Figures 2ac suggest that the association between higher BMI and higher neurometabolite levels was more pronounced in HSs than patients. This was borne out by the linear regressions, which showed significant relationships between greater BMI and higher right Cre and Ins in HSs (Cre: $\mathrm{F}[1]=6.030, P=0.02$ (Figure 2a); Ins: $\mathrm{F}$ $[1]=4.832, P=0.04$ (Figure $2 b)$ ), but not patients (Cre: $F[1]=0.056$, $P=0.81$; Ins: $F[1]=1,777, P=0.19$ ). BMI was not significantly associated with right $\mathrm{Cho}$ in $\mathrm{HSs}$ or patients (Figure 2c). Interestingly, controlling for clinical/treatment variables in patients revealed a relationship between higher $\mathrm{BMI}$ and lower left tNAA ( $\mathrm{F}$ $[1]=5.567, P=0.02$; Figure 2d).

\section{DISCUSSION}

To our knowledge, this was the first study to investigate the relative contributions of $\mathrm{BD}$ diagnosis and elevated $\mathrm{BMI}$ to hippocampal volumes, and only the second (after our glutamate +glutamine study) to investigate their contributions to hippocampal chemistry. We found a diagnosis effect on hippocampal volumes, with patients having smaller hippocampi than HSs, a finding that was most pronounced in the right hippocampus. There was no association between higher BMI and hippocampal volumes. We detected diagnosis- and BMI-related differences in hippocampal chemistry, with patients having lower right $\mathrm{Cre}, \mathrm{MI}$ and Cho, and overweight/obese subjects having higher levels of these chemicals.

Our patient-only models allowed us to control for clinical and treatment factors, and thus enabled us to detect an additional relationship between higher BMI and lower left tNAA in patients that was not apparent in the primary models. One possible explanation for the absence of this finding in the primary models this is a normalizing effect of mood-stabilizing medications on tNAA, which has been reported in previous studies. ${ }^{57-60}$ By this logic, the primary models (patients+HSs) did not find a BMI effect on tNAA because the effect in patients was masked by pharmacotherapy, and there was no effect in HS. The patientonly models, by adjusting for the impact of medications, were able to detect the BMI effect. Thus, increased BMI was associated with altered neurochemistry in patients and HSs, though affecting different neurochemicals in each group.

Together with our previous MRI and MRS studies, the current results demonstrate that $\mathrm{BD}$ diagnosis and higher $\mathrm{BMI}$ both impact brain areas relevant to $B D$. We previously reported that $B D$ patients, but not HS, had BMI-related reductions in total brain WM and total temporal lobe volume. ${ }^{37} \mathrm{GM}$ was relatively spared, but there was a single focus of volume reduction in the right temporal lobe, suggesting that this area may be particularly vulnerable to BMI-related changes. ${ }^{38}$ Moreover, we also found a BMI-related increase in hippocampal glutamate+glutamine in patients. ${ }^{40}$ The consistency of the BMI effect across measures was striking. It is interesting that our current results differ from our previous findings in one important respect. In the previous studies, BMIrelated limbic brain changes were consistently more pronounced in patients than HSs. The current study produced mixed results: higher BMI in patients predicted reduced tNAA, higher BMI in HSs predicted greater Cre and Ins. This suggests that the relationship between BMI and the brain is complex, differing not only between patients and HSs, but also between neurobiological measures.

The mechanisms underlying the relationship between higher $\mathrm{BMI}$ and structural and chemical brain changes in BD are unknown. BMI-related alterations in inflammatory cytokines, adipokines and other biomarkers may play a role. Peripheral inflammation affects brain function via the presence of transport mechanisms for cytokines across the blood-brain barrier, as well as cytokine receptors on the blood-brain barrier and the vagus nerve. ${ }^{61,62}$ Supporting this hypothesis, experimentally induced obesity causes brain inflammation in preclinical models. ${ }^{63}$ Neuroinflammation is increasingly recognized to be important to the etiology of $\mathrm{BD}$, as shown by a recent positron emission tomography study that found hippocampal inflammation in BD patients. ${ }^{64}$ In addition, adipokines such as leptin and adiponectin have receptors in limbic brain areas including the hippocampus and the ventral striatum. ${ }^{65-70}$ Low serum leptin is associated with reduced nucleus accumbens activity, and low serum adiponectin with hippocampal excitotoxicity. ${ }^{6,71-73}$ However, it is also important to remember that the cross-sectional design of the current study means we cannot determine the direction of the link between BMI and the hippocampus. Reverse causality cannot be excluded, particularly in light of the fact that 
a
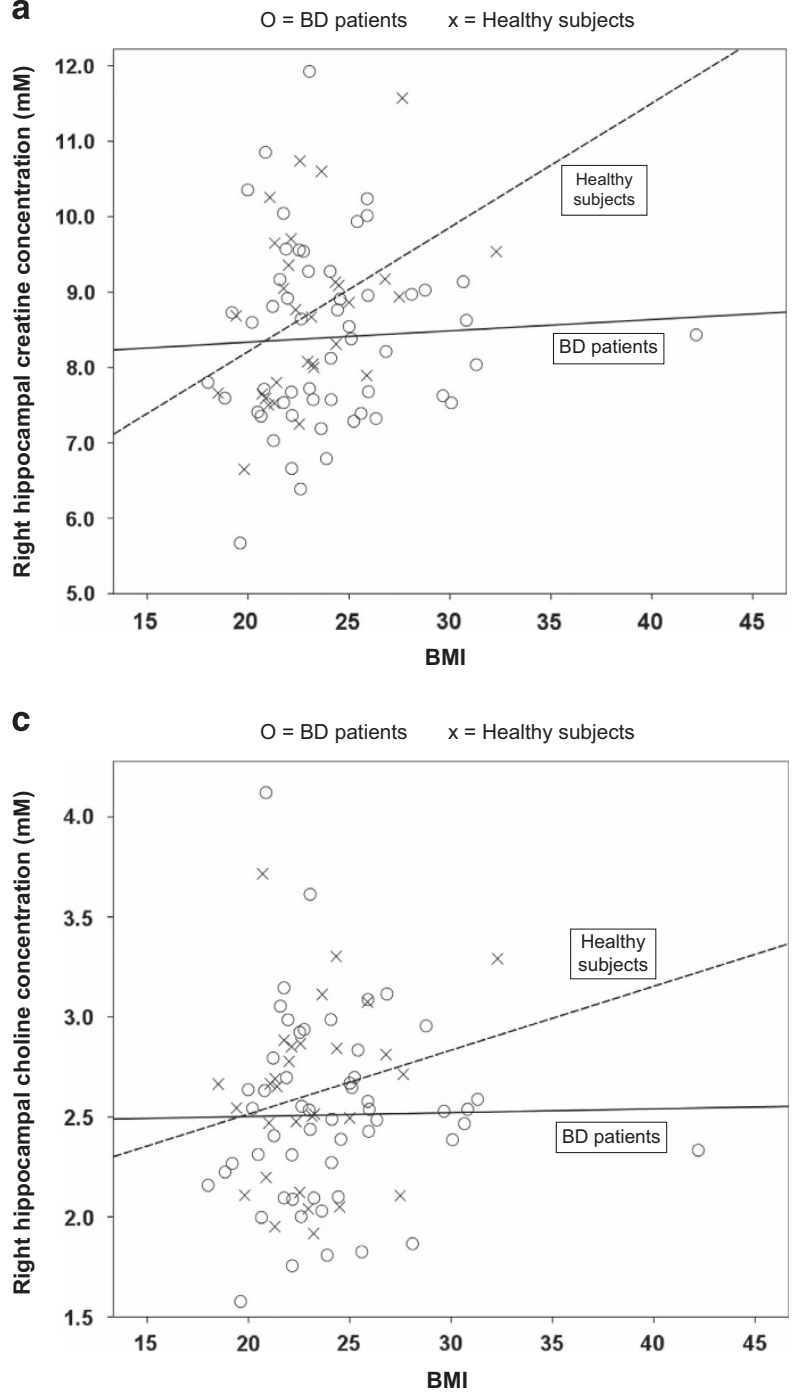

b

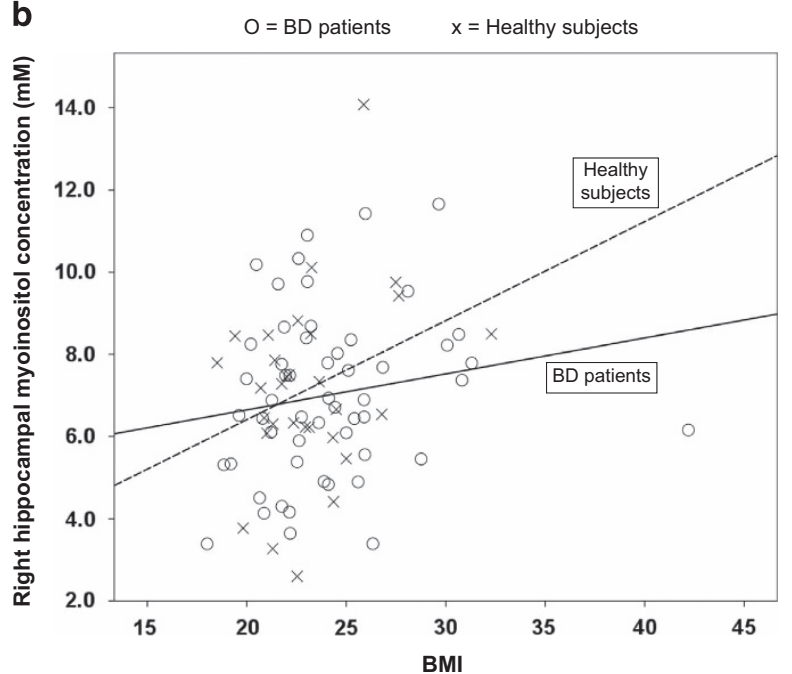

d

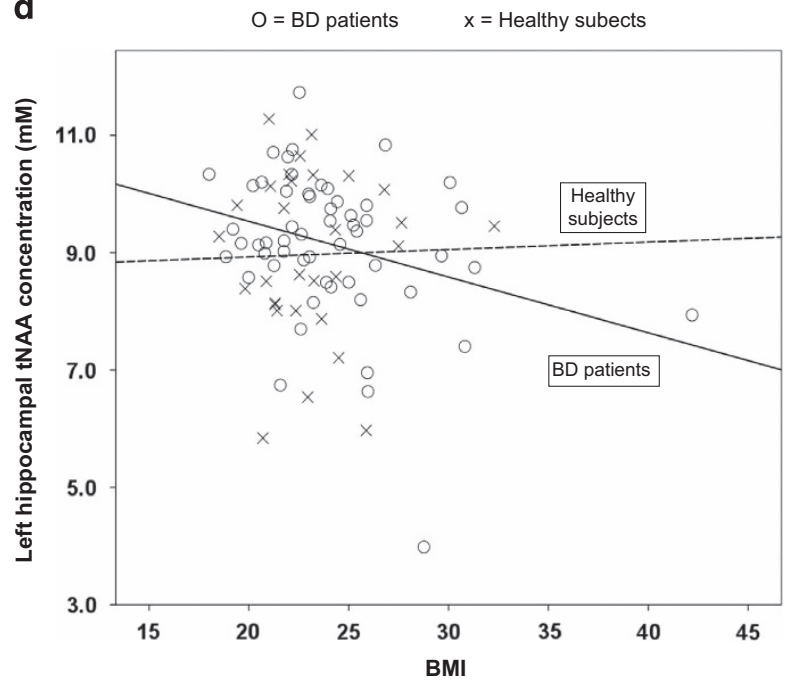

Figure 2. Relationship between body mass index (BMI) and (a) right hippocampal creatine+phosphocreatine, (b) right hippocampal myoinositol, (c) right hippocampal glycerophosphocholine+phosphatidylcholine, and (d) left hippocampal $N$-acetylaspartate+ $N$-acteylaspartylglutamate (tNAA) in bipolar disorder (BD) patients and healthy subjects.

impairment in hippocampal-dependent cognitive functions predicts weight gain. ${ }^{74}$

The hippocampus plays a key role in the pathophysiology of BD. It has reciprocal connections, directly or via the entorhinal cortex, with brain areas involved in the generation and modulation of emotions, including the medial prefrontal cortex, amygdala and ventral striatum. ${ }^{75}$ Current models of $\mathrm{BD}$ conceptualize the hippocampus as a crucial node in a prefrontal-hippocampalamygdala emotion-processing circuit that is underactive in BD. ${ }^{76}$ Our volumetric results are in keeping with meta-analyses of neuroimaging studies that reported reduced hippocampal volumes in $\mathrm{BD} \cdot{ }^{44,77}$ It is more difficult to place the lack of association between $\mathrm{BMI}$ and hippocampal volumes into context, as the relationship between BMI and the hippocampus has been less well studied. All of the investigations so far have been in pediatric or older adult samples and have produced inconsistent results. ${ }^{78-82}$

The neurochemicals we studied are highly relevant to the pathophysiology of BD. NAA is the second most abundant amino acid in the brain after glutamate. It is produced exclusively in neuronal mitochondria and is considered to be a marker of neuron and myelin function and mitochondrial health. ${ }^{83-85}$
Reduced NAA is one of the most consistent neurochemical findings in $\mathrm{BD} .{ }^{85}$ Cre and $\mathrm{PCre}$ exist in equilibrium in a reaction catalyzed by creatine kinase. They are present at high concentrations in cells with large but fluctuating energy demands, such as neurons, where PCre serves as a phosphate donor to synthesize ATP from ADP during periods of high ATP utilization. ${ }^{86}$ A large fraction of creatine kinase is mitochondrial, and alterations in Cre + PCre levels may reflect mitochondrial dysfunction, which is believed to be important to the etiology of BD. ${ }^{87}$ Inositols, mainly Ins, are precursors to myelin and neuronal cell membrane phospholipids such as phosphatidylinositol. They are also components of the phosphoinositol second-messenger system, which regulates intracellular calcium levels and neurotransmitter release. ${ }^{85,88}$ Changes in inositol levels could thus reflect abnormalities in cell membrane biosynthesis or second-messenger cascades involved in cell survival and intracellular trafficking. ${ }^{89}$ Lithium, divalproex and carbamazepine all act on inositol monophosphatase, the final enzyme in Ins synthesis. ${ }^{90}$ Cholines, primarily phosphocholine and glycerophosphocholine, are precursors to phospholipids such as phosphatidylcholine, and to acetylcholine, which is important to memory. Changes in choline 
levels may reflect changes in cell membrane turnover, which can occur in brain illnesses and during neuroinflammation. ${ }^{85,88}$

Nonetheless, studies investigating hippocampal neurochemistry in $\mathrm{BD}$ have produced mixed results. ${ }^{91-106}$ The most consistent finding was reduced NAA, which was detected in $7 / 15$ studies. ${ }^{91-94,97,100,103}$ One study reported increased NAA, ${ }^{102}$ and the remainder found no diagnosis-related differences. None of the five studies that examined Ins found differences between patients and HSs. Increased Cho was detected in 3/13 studies, with the remainder finding no difference between patients and controls. $^{93,102,104}$ Finally, 2/8 studies reported decreased Cre, ${ }^{97,100}$ 1 reported increased $\mathrm{Cre}^{102}$ and the remainder found no diagnosis-related differences. The heterogeneity among study findings may be in part related to small sample sizes, which were $N \leqslant 40$ in 11/16 studies, and differences in illness stage, mood state or pharmacotherapy. Our findings suggest that betweenstudy differences in BMI may also be an important contributing factor.

Strengths of the current study include the following: (1) our well-characterized BD patients and HSs; (2) our first-episode sample, which minimized confounding factors such as variable illness durations, multiple medication trials and high comorbidity rates; and (3) our rigorous quantification of hippocampal volumes and absolute metabolite concentrations. Its limitations include the following: (1) its cross-sectional design; (2) that we did not gather information on factors that might modulate the relationship between BMI and the brain, such as diet, physical activity and smoking, (3) the possibility that random differences in voxel placement created noise in the data, and (4) the limited ability of 3 T MRS to distinguish between closely related molecules, so that, for example, we could not discern low-energy Cre from highenergy PCre.

In conclusion, this report adds to the accumulating evidence that BD diagnosis and elevated BMI both impact brain areas relevant to $\mathrm{BD}$. It also suggests a number of directions for future research. (1) Higher-field-strength MRS (4- T and even 7-T platforms are now available) would permit better differentiation of closely related neurochemicals and thus allow a more precise quantification of the impact of higher BMI on neurochemistry. (2) Novel MRS techniques such as ${ }^{13} \mathrm{C}$-MRS could provide information on neurochemical pathways and functioning to complement the information on concentrations provided by ${ }^{1} \mathrm{H}-\mathrm{MRS}$. (3) Longitudinal studies are urgently needed to determine whether higher $\mathrm{BMI}$ and/or increasing BMI over time lead to progression of neurochemical abnormalities in BD. (4) Finally, whether the relationship between $\mathrm{BMI}$ and the brain is also important in other psychiatric illnesses with high obesity rates, such as major depressive disorder and schizophrenia, requires investigation.

\section{CONFLICT OF INTEREST}

Dr Bond has received speaking/consulting fees or research grants from AstraZeneca, Bristol Myers Squibb, the Canadian Institutes of Health Research (CIHR), the Canadian Network for Mood and Anxiety Treatments (CANMAT), the Canadian Psychiatric Association (CPA), Janssen-Ortho, Myriad Genetics, Otsuka, Pfizer, Sunovion and the University of British Columbia (UBC) Institute of Mental Health/Coast Capital Depression Research Fund. Dr Torres has received speaking/consulting fees or research grants from CIHR, Lundbeck Canada and Sumitomo Dainippon. Dr Honer has been on advisory boards for In Silico, Otsuka/Lundbeck, Roche and Eli Lily. He was additionally supported by the UBC Jack Bell Chair in Schizophrenia. Dr Lam has been on speaker/advisory boards for, or has received research support from AstraZeneca, Bristol Myers Squibb, CANMAT, CPA, CPA Foundation, CIHR, Eli Lilly, Litebook Company, Lundbeck, Lundbeck Institute, Merck, Mochida, Pfizer, Servier, St Jude Medical, UBC Institute of Mental Health/Coast Capital Depression Research Fund, Takeda and Wyeth. Dr Yatham has been on speaker/advisory boards for, or has received research support from AstraZeneca, Bristol Myers Squibb, CANMAT, CIHR, Eli Lilly, GlaxoSmithKline, Janssen, the Michael Smith Foundation for Health Research, Pfizer, Servier and the Stanley Foundation. The remaining authors declare no conflict of interest.

\section{ACKNOWLEDGMENTS}

The data for this manuscript were generated from the Systematic Treatment Optimization Program for Early Mania, which was supported by an unrestricted to LNY from AstraZeneca Canada.

\section{DISCLAIMER}

The sponsor had no input into the design or conduct of the study; collection, management, analysis or interpretation of the data; preparation, review or approval of the manuscript; or decision to submit the manuscript for publication.

\section{REFERENCES}

1 National Institute of Diabetes and Digestive and Kidney Diseases. Overweight and Obesity Statistics. Available at http://www.niddk.nih.gov/health-informa tion/health-statistics/Pages/overweight-obesity-statistics.aspx (accessed 24 October 2015).

2 Guh DP, Zhang W, Bansback N, Amarsi Z, Birmingham CL, Anis AH. The incidence of co-morbidities related to obesity and overweight: a systematic review and meta-analysis. BMC Public Health 2009; 9: 88

3 Field AE, Coakley EH, Must A, Spadano JL, Laird N, Dietz WH et al. Impact of overweight on the risk of developing common chronic diseases during a 10year period. Arch Intern Med 2001; 161: 1581-1586.

4 Lim SS, Vos T, Flaxman AD, Danaei G, Shibuya K, Adair-Rohani H et al. A comparative risk assessment of burden of disease and injury attributable to 67 risk factors and risk factor clusters in 21 regions, 1990-2010: a systematic analysis for the Global Burden of Disease Study 2010. Lancet 2012; 380: 2224-2260.

5 Goldstein BI, Liu SM, Zivkovic N, Schaffer A, Chien LC, Blanco C. The burden of obesity among adults with bipolar disorder in the United States. Bipolar Disord 2011; 13: 387-395.

6 Carney CP, Jones LE. Medical comorbidity in women and men with bipolar disorders: a population-based controlled study. Psychosom Med 2006; 68: 684-691.

7 Johannessen L, Strudsholm U, Foldager L, Munk-Jorgensen P. Increased risk of hypertension in patients with bipolar disorder and patients with anxiety compared to background population and patients with schizophrenia. J Affect Disord 2006; 95: 13-17.

8 Sicras A, Rejas J, Navarro R, Serrat J, Blanca M. Metabolic syndrome in bipolar disorder: a cross-sectional assessment of a Health Management Organization database. Bipolar Disord 2008; 10: 607-616.

9 Lilliker SL. Prevalence of diabetes in a manic-depressive population. Compr Psychiatry 1980; 21: 270-275.

10 Cassidy F, Ahearn E, Carroll BJ. Elevated frequency of diabetes mellitus in hospitalized manic-depressive patients. Am J Psychiatry 1999; 156: 1417-1420.

11 Regenold WT, Thapar RK, Marano C, Gavirneni S, Kondapavuluru PV. Increased prevalence of type 2 diabetes mellitus among psychiatric inpatients with bipolar I affective and schizoaffective disorders independent of psychotropic drug use. $J$ Affect Disord 2002; 70: 19-26.

12 van Winkel R, De Hert M, Van Eyck D, Hanssens L, Wampers M, Scheen A et al. Prevalence of diabetes and the metabolic syndrome in a sample of patients with bipolar disorder. Bipolar Disord 2008; 10: 342-348.

13 Uysal KT, Wiesbrock SM, Marino MW, Hotamisligil GS. Protection from obesityinduced insulin resistance in mice lacking TNF-alpha function. Nature 1997; 389: 610-614.

14 Hotamisligil GS, Shargill NS, Spiegelman BM. Adipose expression of tumor necrosis factor-alpha: direct role in obesity-linked insulin resistance. Science 1993; 259: 87-91.

15 Ouchi N, Parker JL, Lugus JJ, Walsh K. Adipokines in inflammation and metabolic disease. Nat Rev Immunol 2011; 11: 85-97.

16 Rajala MW, Scherer PE. Minireview: the adipocyte--at the crossroads of energy homeostasis, inflammation, and atherosclerosis. Endocrinology 2003; 144: 3765-3773.

17 Kloting N, Bluher M. Adipocyte dysfunction, inflammation and metabolic syndrome. Rev Endocr Metab Disord 2014; 15: 277-287.

18 Gazdzinski S, Millin R, Kaiser LG, Durazzo TC, Mueller SG, Weiner MW et al. BMI and neuronal integrity in healthy, cognitively normal elderly: a proton magnetic resonance spectroscopy study. Obesity 2010; 18: 743-748.

19 Milaneschi Y, Simonsick EM, Vogelzangs N, Strotmeyer ES, Yaffe K, Harris TB et al. Leptin, abdominal obesity, and onset of depression in older men and women. J Clin Psychiatry 2012; 73: 1205-1211.

20 Cazettes F, Cohen Jl, Yau PL, Talbot H, Convit A. Obesity-mediated inflammation may damage the brain circuit that regulates food intake. Brain Res 2011; 1373: 101-109. 
21 Fain JN. Release of inflammatory mediators by human adipose tissue is enhanced in obesity and primarily by the nonfat cells: a review. Mediators Inflamm 2010; 2010: 513948.

22 Banks WA, Farr SA, La Scola ME, Morley JE. Intravenous human interleukin1alpha impairs memory processing in mice: dependence on blood-brain barrier transport into posterior division of the septum. J Pharmacol Exp Ther 2001; 299: 536-541.

23 Banks WA, Kastin AJ, Durham DA. Bidirectional transport of interleukin-1 alpha across the blood-brain barrier. Brain Res Bull 1989; 23: 433-437.

24 Toda N, Ayajiki K, Okamura T. Obesity-induced cerebral hypoperfusion derived from endothelial dysfunction: one of the risk factors for Alzheimer's disease. Curr Alzheimer Res 2014; 11: 733-744.

25 Colman RJ, Anderson RM, Johnson SC, Kastman EK, Kosmatka KJ, Beasley TM et al. Caloric restriction delays disease onset and mortality in rhesus monkeys. Science 2009; 325: 201-204.

26 Enzinger C, Fazekas F, Matthews PM, Ropele S, Schmidt H, Smith S et al. Risk factors for progression of brain atrophy in aging: six-year follow-up of normal subjects. Neurology 2005; 64: 1704-1711.

27 Pedrini S, Thomas C, Brautigam H, Schmeidler J, Ho L, Fraser P et al. Dietary composition modulates brain mass and solubilizable Abeta levels in a mouse model of aggressive Alzheimer's amyloid pathology. Mol Neurodegener 2009; 4: 40.

28 Anstey KJ, Cherbuin N, Budge M, Young J. Body mass index in midlife and latelife as a risk factor for dementia: a meta-analysis of prospective studies. Obes Rev 2011; 12: e426-e437.

29 Munger KL, Chitnis T, Ascherio A. Body size and risk of MS in two cohorts of US women. Neurology 2009; 73: 1543-1550.

30 Hedstrom AK, Olsson T, Alfredsson L. High body mass index before age 20 is associated with increased risk for multiple sclerosis in both men and women Mult Scler 2012; 18: 1334-1336.

31 Abbott RD, Ross GW, White LR, Sanderson WT, Burchfiel CM, Kashon M et al. Environmental, life-style, and physical precursors of clinical Parkinson's disease: recent findings from the Honolulu-Asia Aging Study. J Neurol 2003; 250(Suppl 3): II30-1139.

$32 \mathrm{Hu} \mathrm{G}$, Jousilahti P, Nissinen A, Antikainen R, Kivipelto M, Tuomilehto J. Body mass index and the risk of Parkinson disease. Neurology 2006; 67: 1955-1959.

33 Fagiolini A, Frank E, Houck PR, Mallinger AG, Swartz HA, Buysse DJ et al. Prevalence of obesity and weight change during treatment in patients with bipolar I disorder. J Clin Psychiatry 2002; 63: 528-533.

34 Fagiolini A, Kupfer DJ, Houck PR, Novick DM, Frank E. Obesity as a correlate of outcome in patients with bipolar I disorder. Am J Psychiatry 2003; 160: 112-117.

35 Fagiolini A, Frank E, Scott JA, Turkin S, Kupfer DJ. Metabolic syndrome in bipolar disorder: findings from the Bipolar Disorder Center for Pennsylvanians. Bipolar Disord 2005; 7: 424-430.

36 McElroy SL, Frye MA, Suppes T, Dhavale D, Keck PE, Leverich GS et al. Correlates of overweight and obesity in 644 patients with bipolar disorder. J Clin Psychiatry 2002; 63: 207-213.

37 Bond DJ, Lang DJ, Noronha MM, Kunz M, Torres IJ, Su W et al. The association of elevated body mass index with reduced brain volumes in first-episode mania. Biol Psychiatry 2011; 70: 381-387.

38 Bond DJ, Ha TH, Lang DJ, Su W, Torres IJ, Honer WG et al. Body mass indexrelated regional gray and white matter volume reductions in first-episode mania patients. Biol Psychiatry 2014; 76: 138-145.

39 Kuswanto CN, Sum MY, Yang GL, Nowinski WL, Mclntyre RS, Sim K. Increased body mass index makes an impact on brain white-matter integrity in adults with remitted first-episode mania. Psychol Med 2014; 44: 533-541.

40 Bond DJ, da Silveira LE, MacMillan EL, Torres IJ, Lang DJ, Su W et al. Relationship between body mass index and hippocampal glutamate/glutamine in bipolar disorder. Br J Psychiatry 2016; 208: 146-152.

41 Gigante AD, Bond DJ, Lafer B, Lam RW, Young LT, Yatham LN. Brain glutamate levels measured by magnetic resonance spectroscopy in patients with bipolar disorder: a meta-analysis. Bipolar Disord 2012; 14: 478-487.

42 Haber SN, Knutson B. The reward circuit: linking primate anatomy and human imaging. Neuropsychopharmacology 2010; 35: 4-26.

43 Phelps EA. Human emotion and memory: interactions of the amygdala and hippocampal complex. Curr Opin Neurobiol 2004; 14: 198-202.

44 Otten $M$, Meeter M. Hippocampal structure and function in individuals with bipolar disorder: a systematic review. J Affect Disord 2015; 174: 113-125.

45 Martin AA, Davidson TL. Human cognitive function and the obesogenic environment. Physiol Behav 2014; 136: 185-193.

46 Yatham LN, Kauer-Sant'anna M, Bond DJ, Lam RW, Tam E. Course and outcome after the first manic episode in patients with bipolar disorder: prospective 12-month data from the Systematic Treatment Optimization Program for Early Mania (STOP-EM) project. Can J Psychiatry 2009; 54: 105-112.
47 Sheehan DV, Lecrubier Y, Sheehan KH, Amorim P, Janavs J, Weiller E et al. The Mini-International Neuropsychiatric Interview (M.I.N.I.): the development and validation of a structured diagnostic psychiatric interview for DSM-IV and ICD-10. J Clin Psychiatry 1998; 59(Suppl 20): 22-33.

48 Yatham LN, Kennedy SH, O'Donovan C, Parikh S, MacQueen G, Mclntyre R et al. Canadian Network for Mood and Anxiety Treatments (CANMAT) guidelines for the management of patients with bipolar disorder: Consensus and controversies. Bipolar Disord 2005; 7(Suppl 3): 5-69.

49 Yatham LN, Kennedy SH, Parikh SV, Schaffer A, Beaulieu S, Alda M et al. Canadian Network for Mood and Anxiety Treatments (CANMAT) and International Society for Bipolar Disorders (ISBD) collaborative update of CANMAT guidelines for the management of patients with bipolar disorder: update 2013. Bipolar Disord 2013; 15: 1-44.

50 World Health Organization. Obesity: preventing and managing managing the global epidemic (publication WHO/NUT/NCD/98.1) 1997. whqlibdoc.who.int/hq/ 1998/WHO NUT_NCD 98.1_(p1-158).pdf.

51 Smith SM, Jenkinson M, Woolrich MW, Beckmann CF, Behrens TE, Johansen-Berg $\mathrm{H}$ et al. Advances in functional and structural MR image analysis and implementation as FSL. Neuroimage 2004; 23(Suppl 1): S208-S219.

52 Woolrich MW, Jbabdi S, Patenaude B, Chappell M, Makni S, Behrens T et al. Bayesian analysis of neuroimaging data in FSL. Neuroimage 2009; 45(1 Suppl): S173-S186.

53 Provencher SW. Estimation of metabolite concentrations from localized in vivo proton NMR spectra. Magn Reson Med 1993; 30: 672-679.

54 Posse S, Otazo R, Caprihan A, Bustillo J, Chen H, Henry PG et al. Proton echoplanar spectroscopic imaging of J-coupled resonances in human brain at 3 and 4 Tesla. Magn Reson Med. 2007; 58: 236-244.

55 Kosior RK, Lauzon ML, Federico P, Frayne R. Algebraic T2 estimation improves detection of right temporal lobe epilepsy by MR T2 relaxometry. Neuroimage 2011; 58: 189-197.

56 Kreis R. The trouble with quality filtering based on relative Cramer-Rao lower bounds. Magn Reson Med 2016; 75: 15-18.

57 Hajek T, Bauer M, Pfennig A, Cullis J, Ploch J, O'Donovan C et al. Large positive effect of lithium on prefrontal cortex $\mathrm{N}$-acetylaspartate in patients with bipolar disorder: 2-centre study. J Psychiatry Neurosci 2012; 37: 185-192.

58 Forester BP, Finn CT, Berlow YA, Wardrop M, Renshaw PF, Moore CM. Brain lithium, $\mathrm{N}$-acetyl aspartate and myo-inositol levels in older adults with bipolar disorder treated with lithium: a lithium-7 and proton magnetic resonance spectroscopy study. Bipolar Disord 2008; 10: 691-700.

59 Brambilla P, Stanley JA, Nicoletti MA, Sassi RB, Mallinger AG, Frank E et al. $1 \mathrm{H}$ magnetic resonance spectroscopy investigation of the dorsolateral prefrontal cortex in bipolar disorder patients. J Affect Disord 2005; 86: 61-67.

60 Silverstone PH, Wu RH, O'Donnell T, Ulrich M, Asghar SJ, Hanstock CC. Chronic treatment with lithium, but not sodium valproate, increases cortical $\mathrm{N}$-acetylaspartate concentrations in euthymic bipolar patients. Int Clin Psychopharmacol 2003; 18: 73-79.

61 Dantzer R, O'Connor JC, Freund GG, Johnson RW, Kelley KW. From inflammation to sickness and depression: when the immune system subjugates the brain. Nat Rev Neurosci 2008; 9: 46-56.

62 Capuron L, Miller AH. Immune system to brain signaling: neuropsychopharmacological implications. Pharmacol Ther 2011; 130: 226-238.

63 Drake C, Boutin H, Jones MS, Denes A, McColl BW, Selvarajah JR et al. Brain inflammation is induced by co-morbidities and risk factors for stroke. Brain Behav Immun 2011; 25: 1113-1122.

64 Haarman BC, Riemersma-Van der Lek RF, de Groot JC, Ruhe HG, Klein HC, Zandstra TE et al. Neuroinflammation in bipolar disorder - A [C]-(R)-PK11195 positron emission tomography study. Brain Behav Immun 2014; 40: 219-225.

65 Farr OM, Tsoukas MA, Mantzoros CS. Leptin and the brain: influences on brain development, cognitive functioning and psychiatric disorders. Metabolism 2014; 64: $114-130$.

66 Repunte-Canonigo V, Berton F, Cottone P, Reifel-Miller A, Roberts AJ, Morales M et al. A potential role for adiponectin receptor 2 (AdipoR2) in the regulation of alcohol intake. Brain Res 2010; 1339: 11-17.

67 Harvey J. Leptin: a diverse regulator of neuronal function. J Neurochem 2007; 100: 307-313.

68 Jeon BT, Shin HJ, Kim JB, Kim YK, Lee DH, Kim KH et al. Adiponectin protects hippocampal neurons against kainic acid-induced excitotoxicity. Brain Res Rev 2009; 61: 81-88.

69 Yau SY, Li A, Hoo RL, Ching YP, Christie BR, Lee TM et al. Physical exerciseinduced hippocampal neurogenesis and antidepressant effects are mediated by the adipocyte hormone adiponectin. PNAS 2014; 111: 15810-15815.

70 Garza JC, Guo M, Zhang W, Lu XY. Leptin increases adult hippocampal neurogenesis in vivo and in vitro. $J$ Biol Chem 2008; 283: 18238-18247.

71 Jastreboff AM, Lacadie C, Seo D, Kubat J, Van Name MA, Giannini C et al. Leptin is associated with exaggerated brain reward and emotion responses to food images in adolescent obesity. Diabetes Care 2014; 37: 3061-3068. 
72 Grosshans M, Vollmert C, Vollstadt-Klein S, Tost H, Leber S, Bach P et al. Association of leptin with food cue-induced activation in human reward pathways. Arch Gen Psychiatry 2012; 69: 529-537.

73 Masaki T, Anan F, Shimomura T, Fujiki M, Saikawa T, Yoshimatsu H. Association between hippocampal volume and serum adiponectin in patients with type 2 diabetes mellitus. Metabolism 2012; 61: 1197-1200.

74 Davidson TL, Hargrave SL, Swithers SE, Sample CH, Fu X, Kinzig KP et al. Interrelationships among diet, obesity and hippocampal-dependent cognitive function. Neuroscience 2013; 253: 110-122.

75 Small SA, Schobel SA, Buxton RB, Witter MP, Barnes CA. A pathophysiological framework of hippocampal dysfunction in ageing and disease. Nat Rev Neurosci 2011; 12: 585-601.

76 Phillips ML, Swartz HA. A critical appraisal of neuroimaging studies of bipolar disorder: toward a new conceptualization of underlying neural circuitry and a road map for future research. Am J Psychiatry 2014; 171: 829-843.

77 Hallahan B, Newell J, Soares JC, Brambilla P, Strakowski SM, Fleck DE et al. Structural magnetic resonance imaging in bipolar disorder: an international collaborative mega-analysis of individual adult patient data. Biol Psychiatry 2011; 69: 326-335.

78 Janowitz D, Wittfeld K, Terock J, Freyberger HJ, Hegenscheid K, Volzke H et al. Association between waist circumference and gray matter volume in 2344 individuals from two adult community-based samples. Neuroimage 2015; 122: 149-157.

79 Cherbuin N, Sargent-Cox K, Fraser M, Sachdev P, Anstey KJ. Being overweight is associated with hippocampal atrophy: the PATH Through Life Study. Int J Obes 2015; 39: 1509-1514.

80 Bauer CC, Moreno B, Gonzalez-Santos L, Concha L, Barquera S, Barrios FA. Child overweight and obesity are associated with reduced executive cognitive performance and brain alterations: a magnetic resonance imaging study in Mexican children. Pediatr Obes 2015; 10: 196-204.

81 Debette S, Wolf C, Lambert JC, Crivello F, Soumare A, Zhu YC et al. Abdominal obesity and lower gray matter volume: a Mendelian randomization study. Neurobiol Aging 2014; 35: 378-386.

82 Widya RL, de Roos A, Trompet S, de Craen AJ, Westendorp RG, Smit JW et al. Increased amygdalar and hippocampal volumes in elderly obese individuals with or at risk of cardiovascular disease. Am J Clin Nutr 2011; 93: 1190-1195.

83 Baslow $\mathrm{MH}$. N-acetylaspartate in the vertebrate brain: metabolism and function. Neurochem Res 2003; 28: 941-953.

84 Nordengen K, Heuser C, Rinholm JE, Matalon R, Gundersen V. Localisation of $\mathrm{N}$-acetylaspartate in oligodendrocytes/myelin. Brain Struct Funct 2015; 220: 899-917.

85 Maddock RJ, Buonocore MH. MR spectroscopic studies of the brain in psychiatric disorders. Curr Top Behav Neurosci 2012; 11: 199-251.

86 Andres RH, Ducray AD, Schlattner U, Wallimann T, Widmer HR. Functions and effects of creatine in the central nervous system. Brain Res Bull 2008; 76: 329-343.

87 Scaini G, Rezin GT, Carvalho AF, Streck EL, Berk M, Quevedo J. Mitochondrial dysfunction in bipolar disorder: evidence, pathophysiology and translational implications. Neurosci Biobehav Rev 2016; 68: 694-713.

88 Rae CD. A guide to the metabolic pathways and function of metabolites observed in human brain 1H magnetic resonance spectra. Neurochem Res 2014; 39: 1-36.

89 Soeiro-de-Souza MG, Dias WV, Figueira ML, Forlenza OV, Gattaz WF, Zarate CA Jr et al. Translating neurotrophic and cellular plasticity: from pathophysiology to improved therapeutics for bipolar disorder. Acta Psychiatr Scand 2012; 126: 332-341.

90 Williams RS, Cheng L, Mudge AW, Harwood AJ. A common mechanism of action for three mood-stabilizing drugs. Nature 2002; 417: 292-295.

91 Atmaca M, Yildirim H, Ozdemir H, Poyraz AK, Tezcan E, Ogur E. Hippocampal 1H MRS in first-episode bipolar I patients. Prog Neuropsychopharmacol Biol Psychiatry 2006; 30: 1235-1239.

92 Atmaca M, Yildirim H, Ozdemir H, Ogur E, Tezcan E. Hippocampal 1H MRS in patients with bipolar disorder taking valproate versus valproate plus quetiapine. Psychol Med 2007; 37: 121-129.
93 Atmaca M, Yildirim H. Altered neurochemical ingredient of hippocampus in patients with bipolar depression. Depress Res Treat 2012; 2012: 485249.

94 Bertolino A, Frye M, Callicott JH, Mattay VS, Rakow R, Shelton-Repella J et al. Neuronal pathology in the hippocampal area of patients with bipolar disorder: a study with proton magnetic resonance spectroscopic imaging. Biol Psychiatry 2003; 53: 906-913.

95 Chitty KM, Lagopoulos J, Hickie IB, Hermens DF. Hippocampal glutamatergic/ NMDA receptor functioning in bipolar disorder: a study combining mismatch negativity and proton magnetic resonance spectroscopy. Psychiatry Res 2015; 233: 88-94.

96 Colla M, Schubert F, Bubner M, Heidenreich JO, Bajbouj M, Seifert F et al. Glutamate as a spectroscopic marker of hippocampal structural plasticity is elevated in long-term euthymic bipolar patients on chronic lithium therapy and correlates inversely with diurnal cortisol. Mol Psychiatry 2009; 14: 696-704.

97 Deicken RF, Pegues MP, Anzalone S, Feiwell R, Soher B. Lower concentration of hippocampal $\mathrm{N}$-acetylaspartate in familial bipolar I disorder. Am J Psychiatry 2003; 160: 873-882.

98 Gigante AD, Lafer B, Yatham LN. (1)H-MRS of hippocampus in patients after first manic episode. World J Biol Psychiatry 2014; 15: 145-154.

99 Gruber O, Hasan A, Scherk H, Wobrock T, Schneider-Axmann T, Ekawardhani S et al. Association of the brain-derived neurotrophic factor val66met polymorphism with magnetic resonance spectroscopic markers in the human hippocampus: in vivo evidence for effects on the glutamate system. Eur Arch Psychiatry Clin Neurosci 2012; 262: 23-31.

100 Haarman BC, Burger H, Doorduin J, Renken RJ, Sibeijn-Kuiper AJ, Marsman JC et al. Volume, metabolites and neuroinflammation of the hippocampus in bipolar disorder - a combined magnetic resonance imaging and positron emission tomography study. Brain Behav Immun 2015; 56: 21-33.

101 Hermens DF, Naismith SL, Chitty KM, Lee RS, Tickell A, Duffy SL et al. Cluster analysis reveals abnormal hippocampal neurometabolic profiles in young people with mood disorders. Eur Neuropsychopharmacol 2015; 25: 836-845.

102 losifescu DV, Moore CM, Deckersbach T, Tilley CA, Ostacher MJ, Sachs GS et al. Galantamine-ER for cognitive dysfunction in bipolar disorder and correlation with hippocampal neuronal viability: a proof-of-concept study. CNS Neurosci Ther 2009; 15: 309-319.

103 Scherk H, Backens M, Schneider-Axmann T, Kemmer C, Usher J, Reith W et al. Neurochemical pathology in hippocampus in euthymic patients with bipolar I disorder. Acta Psychiatr Scand 2008; 117: 283-288.

104 Senaratne R, Milne AM, MacQueen GM, Hall GB. Increased choline-containing compounds in the orbitofrontal cortex and hippocampus in euthymic patients with bipolar disorder: a proton magnetic resonance spectroscopy study. Psychiatry Res 2009; 172: 205-209.

105 Zanetti MV, Otaduy MC, de Sousa RT, Gattaz WF, Busatto GF, Leite CC et al. Bimodal effect of lithium plasma levels on hippocampal glutamate concentrations in bipolar II depression: a pilot study. Int J Neuropsychopharmacol 2014; 18: pii: pyu058.

106 Zhong S, Wang Y, Zhao G, Xiang Q, Ling X, Liu S et al. Similarities of biochemical abnormalities between major depressive disorder and bipolar depression: a proton magnetic resonance spectroscopy study. J Affect Disord 2014; 168: 380-386.

This work is licensed under a Creative Commons Attribution 4.0 International License. The images or other third party material in this article are included in the article's Creative Commons license, unless indicated otherwise in the credit line; if the material is not included under the Creative Commons license, users will need to obtain permission from the license holder to reproduce the material. To view a copy of this license, visit http://creativecommons.org/licenses/ by/4.0/

(c) The Author(s) 2017

Supplementary Information accompanies the paper on the Translational Psychiatry website (http://www.nature.com/tp) 